\title{
Erratum to: How does working on university-industry collaborative projects affect science and engineering doctorates' careers? Evidence from a UK research-based university
}

\author{
Hsing-fen Lee $\cdot$ Marcela Miozzo
}

Published online: 7 June 2014

(C) Springer Science+Business Media New York 2014

\section{Erratum to: J Technol Transf DOI 10.1007/s10961-014-9340-4}

The original version of this article unfortunately contained a mistake. The presentation of Table 3 was incorrect. A horizontal line was placed at the wrong position in the table. The correct table is given below.

The online version of the original article can be found under doi:10.1007/s10961-014-9340-4.

H. Lee $(\bowtie)$

Department of International Management and Innovation, Middlesex University Business School, Middlesex University, The Burroughs, Hendon, London NW4 4BT, UK

e-mail: h.lee@mdx.ac.uk

M. Miozzo

Manchester Business School, Manchester Institute of Innovation Research, University of Manchester, Booth Street West, Manchester M15 6PB, UK 


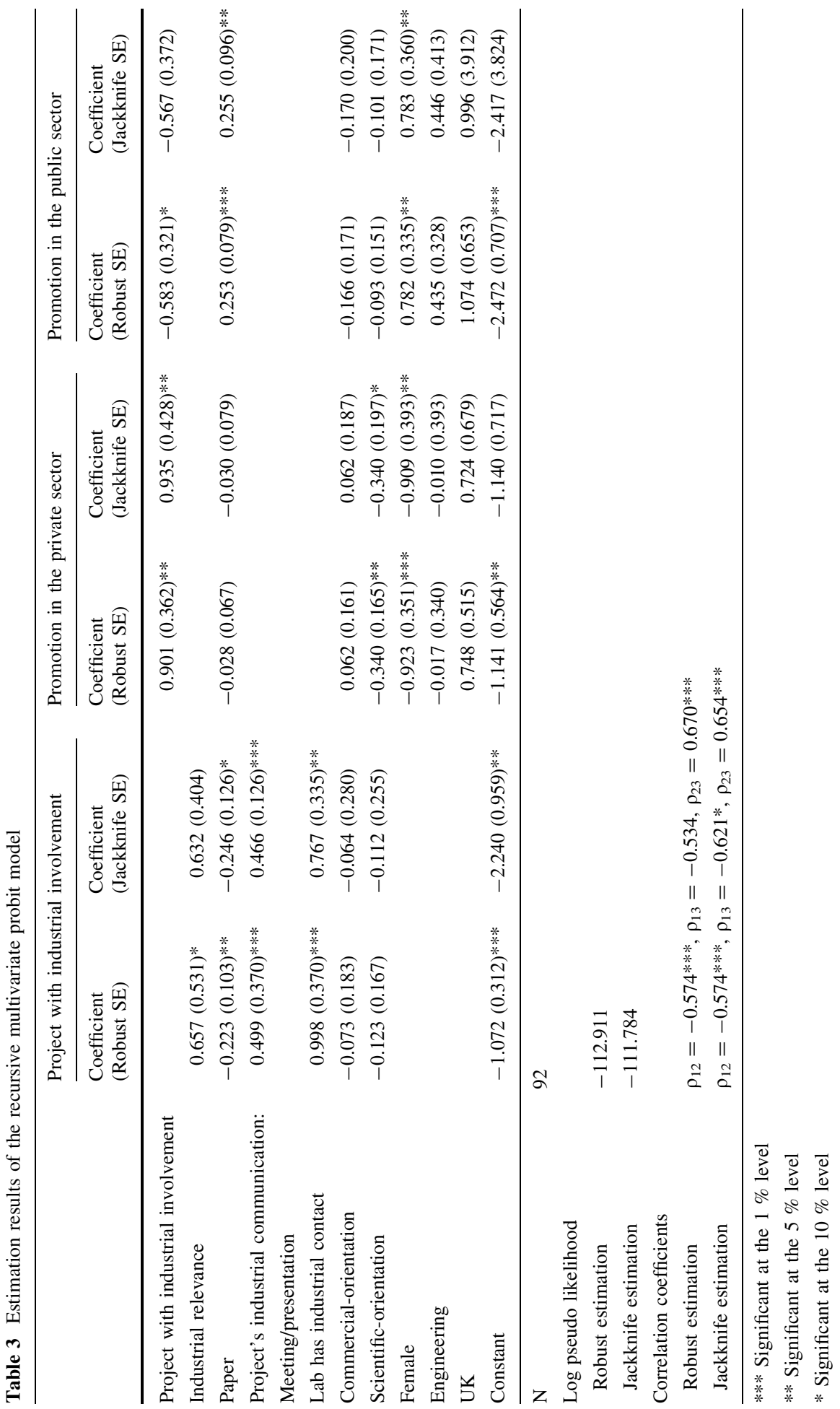

